\title{
Modeling Behavioral Tendencies of the Horse Racing Spectators in Gonbad Kvaoos Spring Competition Based on Planned Behavior Model
}

\author{
${ }^{1}$ Fatemeh Dankoub Korpi, ${ }^{1}$ Akram Esfahani Nia ${ }^{*}{ }^{2}$ Nasser Bai, ${ }^{1}$ Habib Asgharpour \\ ${ }^{1}$ Department of Physical Education and Sports Sciences, Aliabad Katoul Branch, Islamic Azad University, \\ Aliabad Katoul, Iran. ${ }^{2}$ Department of Physical Education and Sport Sciences, Azadshahr Branch, Islamic \\ Azad University, Azadshahr, Iran.
}

Submitted 21 July 2019; Accepted in final form 22 September 2019.

\begin{abstract}
Background. Horse riding is one of the oldest sports competition in Iran held annually in provinces such as Golestan. However, the number of spectators present in these competitions is not comparable to sports such as football. Objectives. It's necessary to study the behavioral tendencies of the Spectators of horse racing and its influencing factors. Methods. It was a descriptive survey study and the statistical population included all spectators of horse racing of the Eighth Week Spring competition in Gonbad Kavoos, 2018 which included 3480 individuals. According to Cochran formula, 348 people were selected by available sampling method. Cheng et al. (2012) questionnaire was used for data collection of planned behavior model and Lee and Shiu (2015) questionnaire for tendency of spectator's involvement at sporting event and spectators' re-attendance questionnaire of Rio and et al (2011) were used. The internal consistencies of the questionnaires were obtained by Cronbach's which were $0.89,0.85$ and 0.78 , respectively. Structural equation modeling was used to test the research model. Results. The findings showed that the effect of attitude $(\beta=0.23, \mathrm{t}=3.74)$, subjective norms $(\beta=0.15, \mathrm{t}=2.78)$ and perceived behavior control $(\beta=0.35, \mathrm{t}=-5.93)$ were positive and significant on the tendency of involvement of spectator in Horse Racing. Moreover, the effect of attitude $(\beta=0.34, \mathrm{t}=6.55)$ and perceived behavior control $(\beta=0.04, \mathrm{t}=0.83)$ were positive and significant on the spectators' re-attendance to Horse Racing. Finally, the findings showed that the effect of subjective norms was not significant on the spectators' re-attendance $(\beta=0.16, t=2.37)$. Conclusion. It can be concluded that the planned behavior model can be used to explain the behavioral tendencies of horse racing spectators during the Gonbad kavoos spring competition. Finally, increasing spectators' knowledge of horse racing, offering attractive and entertaining programs for spectators during competitions and developing various promotional strategies to increase involvement and a desire for Horse Racing Spectators re-attendance are suggested for these competitions.
\end{abstract}

\section{KEYWORDS: Re-attendance, Involvement, Perceived Behavior, Mental Norms, Attitude, Horse Racing Spectators}

\section{INTRODUCTION}

Today, the sports industry holds a prominent place among industries, and its role in the economic growth of countries, especially developed countries, is increasing. Statistics show that in 2015 alone, the worldwide sports industry turnover was over $\$ 600$ billion dollars, which has contributed significantly to the gross domestic product of leading countries (1). Many factors, such as the arrival of sponsors, sports leagues, sports clubs and sport tourism, have contributed to the development of the sports industry (2). Along with other factors, sports consumers also

*. Corresponding Author:

Akram Esfahani Nia, Assistant Professor

E-mail: akramesf59@gmail.com 
play an important role in the development of this industry (3). Spectators are one of the most important consumers of the sports industry. The presence of spectators not only enhances the attractiveness of sporting events, but also brings many financial benefits that have attracted the attention of sports executives and marketers (4).

Spectators attendance is vital to direct and indirect revenue generation for sports clubs; so awareness of spectators' motivations, attitudes, and behaviors regarding the event or during the event are important to increase their support of their favorite sports club and generate more revenue (5). Attention to emotions and the needs of the Spectators participating in sporting events (5), the quality of sporting events (6) and the spectators satisfaction of a sporting event (7) are some of the factors that can shape and replicate positive behaviors in spectators (8). On the other hand, it is important to study the behavior of sport consumers and what influences their choice, as the ultimate goal of producing and selling sports products and services is to obtain customer satisfaction and loyalty and to continue to profit (9). Studying the behaviors of Spectators has been an important part of Sports Marketing Research for the past few years (10). Given the importance of Spectators as one of the most important consumers of the sports industry, studying their behaviors has devoted a significant portion of sports marketing research to answers to the questions of whether behavioral tendencies of the Spectators in sports environments are predictable or not and what factors affect them (11).

Behavioral Tendencies of the Spectators indicate their readiness to perform certain behaviors, to tune and quantify their behavior. Behavioral tendencies can be defined as a mental likelihood that occurs in one's favorite behavior such as getting involved in the event and return to the event (12).

One of the most important behavioral tendencies of the Spectators is Getting Involved in the Event. Getting involved in the Event is defined as Spectators' participation in a sporting event when this partnership is one of the central and valuable components of their lives. This type of involvement includes things like an interest in the event, a moment to start the event, wearing an event uniform, talking about the event with others, enjoying the event, being with friends at the event, and offering the event to others (13). Chao-Sen (2018) defined getting involved in the
Event as the degree of motivation, importance, or concern for the events that interest him (14). Getting involved in the Event is also associated with inner emotions and engages Spectators' thinking and emotions (15).

Mental and Emotional Involvement of the Spectators influence a person's decisions and behaviors with a sport event (16). Spectators enjoy the excitement and joy of the ongoing involvement in sports activities and events which can lead to more happiness and satisfaction (17). Therefore, Involvement of Spectators and their participation in sporting events can be useful for sports marketers to understand the factors influencing a spectator's decision towards a sporting event such as their willingness to buy tickets and participating in a sporting event (18). Another behavioral tendencies of the Spectators that is very important for sport event managers is their re-attendance because this behavior plays a very important role in event profitability and is the most reliable indicator for predicting real spectators presence (19). The tendency to return is defined as the intention of the spectators to reattending the event. The attraction of spectators will be effective as an important revenuegenerating strategy if they are not temporarily present at the event and return to the event for reviewing (20).Re-attending spectators brings economic benefits such as reduced marketing and executive costs, the ability to maintain profit margins without lowering prices, increasing purchases over time, and reducing absorption costs (21).

Byon et al (2013) argued that the consequences of Spectators re-attending sporting events are not limited to financial matters, and include many non-financial consequences, such as the development of individual, social, and cultural factors, which raise awareness of the causes of attendance and effective factors. This makes it necessary for them to re-attend sporting events (22). Understanding Spectators' desires is the main variable moderating their attitude towards the event and their perception of event quality and their satisfaction, which ultimately guarantees Spectators re-attendance (23). There are many factors that can influence the behavioral consequences of Spectators at sporting events (24), including the theory of planned behavior. Theory of Planned Behavior studies consumer behavior in a variety of settings, including sports, and suggests that individuals' behaviors can be 
described and predicted through attitudes, perceived behavior control, and their subjective norms (25). Attitude toward behavior indicates a positive or negative assessment of the behavior one intends to do (26). Sports Spectators whose attitudes to event are positive and emotionally event-related are likely to participate in many event-related activities, and this positive attitude to sporting events is a major predictor of their behavior towards a sporting event (27).

On the other hand, perceived behavioral control indicates to what extent a person can control his or her behavior at will (28). The concept of perceived behavioral control often reflects one's assessment of various capacities, such as skills, abilities, and limiting or facilitating factors such as barriers and access to opportunities for one's behavior in a sporting event (29). Perceived behavioral control content may represent factors such as time, traffic, money, and schedule that have a direct impact on behavioral intention. For example, if the spectator's residence is near the stadium, it is easy for him to attend a sporting event, while participation and getting involved in the sporting event may be difficult for a person who does not live near the stadium (30). Finally, subjective norms include the opinions and suggestions of influential individuals (such as parents, spouses, friends, and classmates) on the desired behavior (31). Subjective norms indicate the importance of the social pressures of those around the formation of behaviors associated with a sporting event, such as a tendency to involvement and a tendency to re-attending for spectator (32). If one is able to understand the particular behaviors of important people in their lives, such as family, friends, and peers, these behaviors are not unexpectedly influenced by them (33). For Bakhsh (2018), understanding the subjective norms associated with the activity of family and friends of Sports Spectators is the strongest predictor of getting involved in the sport Event (34).

Potwarka \& McCarville (2010) believe that the theory of planned behavior is one of the most appropriate motivational theories in explaining the behaviors of sports event spectators, including getting Involved in the Event and their desire to return (35). Increasing the number of Spectators involved in or re-attending a sporting event is a top priority for any event. This Involvement may include Sports Spectators attending a sporting event, or it may include a sports manager providing the appropriate space for a sporting event (36). Various studies have been conducted on planned behavior and its role in shaping the behavioral tendencies of individuals in sports environments. Parsamehr (2014) found that three factors of attitude, control of perceived behavior and subjective norms are able to predict intention and behavior of participants in sport (37). The results of Matlabi et al.'s (2014) study, which used the theory of planned behavior to promote physical activity and exercise behavior among older adults, showed that subjective norms and perceived behavioral control are the most powerful determinants of sporting behavior in older people (38). The results of Chen Lu et al.'s (2011) research showed that three factors of attitude, subjective norms, and perceived behavior control had a positive and significant effect on the Behavioral Tendencies of the Spectators of volleyball matches (32).

In a study by Cheng et al. (2012) on the behavior and involvement of Spectators in baseball, they found that perceived attitudes and behavioral control influenced Spectators Involvement in an event (39). Chan et al. (2014) examined the application of the Theory of Planned Behavior to predicting recreational sport activities among students in Malaysia, and concluded that there was a significant relationship between attitudinal variables and subjective norms with behavioral intention to participate in recreational sport activities and, also, there was a significant relationship between perceived behavioral control and students' intention to participate (40).

Samida et al. (2014) stated that attitudes influence the future presence of Spectators in professional sporting events, and the unique behaviors of each team can influence Spectators re-attendance (41). Wu (2015) conducted a study using the Theory of Planned Behavior to explain and predict the behavior of water sports promotion in Taiwan and found that attitudes and subjective norms had no significant effect on behavioral intentions and willingness to return of Spectators, but perceived behavioral control had a significant impact on the willingness to return of Spectators (42). Adosari et al. (2015) found that there was a relationship between the dimensions of planned behavior and the intention of Spectators to participate in professional football matches among Saudi football spectators (25). 
Kim and James (2016) examined the role of the theory of planned behavior on Spectators' intention to buy sports teams' products and found that there was a positive relationship between the theory of planned behavior and Spectators' intention to purchase (43). Bakhsh (2018) investigated the effect of planned behavior theory on sport Involvement of Spectators and concluded that there was a significant relationship between attitudes and subjective norms with participation and Involvement of Spectators at sport event and there was no relationship between perceived behavioral control and involvement (34). Nowadays, attention to Behavioral Tendencies of the Spectators is not just focused on specific sporting events, and Spectators are an integral part of any sporting event. Horse Racing is one of the sporting events that has attracted many Spectators. For example, in 2016, in Ireland, 1.3 million spectators visited Horse Racing, which led to a revenue of 1.84 billion euros and created 28,900 direct and indirect job opportunities during the competition (44). Horse Racing in Canada's in 2010 was also estimated generate a revenue of around $\$ 5.7$ billion, with much of the revenue coming from Spectators (45), illustrating the importance of these competitions in different countries and that the Spectators play an important role in the development of this sport.

Given the historical background of horse breeding and horse racing in Iran, the scientific and economic interest in this sport has received less attention than other disciplines. The attractiveness of Horse Racing and its association with the culture of different ethnic groups of the people of Iran, including Golestan province, are some of the factors that can make this sporting event progress. Paying attention to the reasons people attend this unique sporting event in the country as a spectator can play an important role in the development of these competitions. However, there has been no comprehensive research on the Behavioral Tendencies of the Spectators of Horse Racing, such as the tendency to involvement and the willingness to return and the factors affecting it in the country, which makes this research important. Therefore, considering the importance of the research topic and the existence of scientific gaps in this field, the main purpose of this research was to model the Behavioral Tendencies of the Spectators of Horse Racing in spring competition based on the planned behavior model.

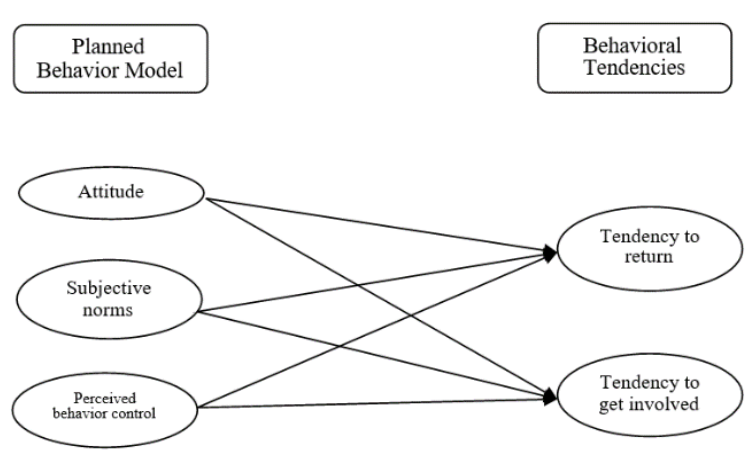

Figure 1. Conceptual Model of Research

\section{MATERIALS AND METHODS}

Study Design. It was an applied descriptive study.

Participants. The statistical population of the study included all Spectators of Horse Racing in the eighth week of the Spring in Gonbad Kavoos consisting of 3480 individuals, in 2018. The size of the population was determined by the number of tickets sold. It is noteworthy that Horse Racing was held in ten weeks in the Spring. The sample size was 347 using Cochran formula. Available sampling method was used to select the subjects.

Research Instrument. Cheng et al (2012) questionnaire was used for the planned behavior model and for behavioral tendencies of the spectators, Lee \& Shiu (2015) Involvement of Spectators and Ryu et al (2011) Sport Spectators willingness to Return were used. The planned behavior model questionnaire had 15 items and three components of attitude, subjective norms and perceived behavior control, each of which had 5 items and was measured on a 5-point Likert scale. The involvement of spectators and willingness to return questionnaires had 8 and 4 items, respectively, which were measured on a 5point Likert scale.

Data Collection. In order to determine the content validity of the research questionnaires, the opinions of 5 sport management professors were used and then to determine the reliability of the questionnaires, a preliminary study (by completing the questionnaires by 40 Spectators of Horse Racing in seventh week) was conducted. The reliability coefficients of these questionnaires were estimated 0.89, 0.85 and 0.78, respectively, using Cronbach's alpha for planned behavior model questionnaires, tendency to be involved in the event, and willingness to return. It indicated the reliability of the measuring instrument. In another part of the questionnaire, demographic information such as age, educational 
degree and background of the subjects were collected while watching Horse Racing. After determining the validity and reliability of the instruments, questionnaires were distributed among the research sample in coordination with the Horsing Board of Gonbad Kavoos.

Statistical Analysis. In this study, descriptive statistics including frequency, mean and standard deviation were used to organize, summarize, and classify data. The results of Kolmogorov-Smirnov test showed that the distribution of data was not normal in the research variables, so structural equation modeling was used to test the research model. For this purpose, PLS software version 3 was used. To analyze patterns in Structural Equation Method with partial least squares approach, one first has to check the fit of the measurement model and then test the research structural model (46).

The fitness of the measurement model was evaluated by considering three criteria of reliability, convergent validity and divergent validity. To evaluate the reliability, Composite Reliability (CR) indices, mean variance extracted and factor loadings were used. If the composite reliability value is greater than 0.7 , the mean extracted variance is greater than 0.5 , and the factor loadings are greater than 0.5 , the reliability of the measurement models is confirmed (47).

\section{RESULTS}

Concerning demographic characteristics, the results showed that most of the subjects were in the age group of 20-30 years (108 persons). Also, most of the subjects had a diploma degree $(\mathrm{n}=$ 170). Finally, the results showed that the highest frequency of Horse Racing watching experience belonged to the group of $1-10$ years $(n=157)$. Mean of planned behavior model, Involvement of Spectators in competition and willingness to return were $3.91 \pm 0.55,4.01 \pm 0.59$ and $4.13 \pm$ 0.65 , respectively.

According to the results of Table 1, the reliability of the research measurement models was at an optimum level. Also, as the composite reliability values were higher than the baseline criterion (0.7), so the research constructs had acceptable convergent validity. It is noteworthy that questions 16 and 17 related to the Involvement of Spectators were omitted because of low factor loadings. For a structure to have an acceptable diagnostic or divergent validity, the root mean square of the variance extracted from the structure must be greater than its correlation with other structures (48).

Table 1. Reliability Indices of Research Structures

\begin{tabular}{|c|c|c|c|c|c|}
\hline Item & $\begin{array}{c}\text { Factor } \\
\text { load }\end{array}$ & t-value & $\begin{array}{c}\text { Mean variance } \\
\text { extracted }\end{array}$ & $\begin{array}{l}\text { Combined } \\
\text { reliability }\end{array}$ & $\begin{array}{c}\text { Cronbach's } \\
\text { alpha }\end{array}$ \\
\hline Attitude & & & 0.59 & 0.77 & 0.89 \\
\hline 1 & 0.58 & 8.11 & & & \\
\hline 2 & 0.70 & 13.33 & & & \\
\hline 3 & 0.67 & 13.69 & & & \\
\hline 4 & 0.61 & 11.32 & & & \\
\hline 5 & 0.61 & 9.68 & & & \\
\hline Subjective norms & & & 0.67 & 0.85 & 0.86 \\
\hline 6 & 0.66 & 13.81 & & & \\
\hline 7 & 0.68 & 12.18 & & & \\
\hline 8 & 0.76 & 19.18 & & & \\
\hline 9 & 0.81 & 28.09 & & & \\
\hline 10 & 0.72 & 18.69 & & & \\
\hline Perceived behavior control & & & 0.63 & 0.94 & 0.91 \\
\hline 11 & 0.64 & 12.73 & & & \\
\hline 12 & 0.61 & 11.67 & & & \\
\hline 13 & 0.75 & 22.29 & & & \\
\hline 14 & 0.71 & 14.70 & & & \\
\hline 15 & 0.64 & 10.86 & & & \\
\hline Fans tend to get involved in the competition & & & 0.58 & 0.87 & 0.87 \\
\hline 18 & 0.54 & 9.46 & & & \\
\hline 19 & 0.62 & 11.90 & & & \\
\hline 20 & 0.56 & 8.60 & & & \\
\hline 21 & 0.71 & 16.07 & & & \\
\hline 22 & 0.74 & 21.58 & & & \\
\hline 23 & 0.69 & 16.93 & & & \\
\hline Fans tend to return & & & 0.52 & 0.80 & 0.76 \\
\hline 24 & 0.63 & 9.42 & & & \\
\hline 25 & 0.72 & 15.35 & & & \\
\hline 26 & 0.73 & 19.96 & & & \\
\hline 27 & 0.72 & 16.10 & & & \\
\hline
\end{tabular}


Table 2. Results of Diagnostic Validity of Research Structures

\begin{tabular}{|llcccc|c|}
\hline Structures & $\mathbf{1}$ & $\mathbf{2}$ & $\mathbf{3}$ & $\mathbf{4}$ & $\mathbf{5}$ \\
$\mathbf{1}$ & Attitude & 0.77 & & & & \\
$\mathbf{2}$ & Subjective norms & 0.64 & 0.82 & & & \\
$\mathbf{3}$ & Perceived behavior control & 0.59 & 0.68 & 0.79 & & \\
$\mathbf{4}$ & Fans tend to get involved in the competition & 0.59 & 0.64 & 0.72 & 0.76 & \\
$\mathbf{5}$ & Fans tend to return & 0.66 & 0.71 & 0.64 & 0.59 & 0.72 \\
\hline
\end{tabular}

Table 3. Results of Investigating the Validity Index of Research Structures

\begin{tabular}{|lccc|}
\hline Structural statistics & SSO & SSE & 1-SSE/SSO \\
Attitude & 297.85 & 226.69 & 0.31 \\
Subjective norms & 274.46 & 227.54 & 0.21 \\
Perceived behavior control & 288.79 & 251.12 & 0.15 \\
Fans tend to get involved in the competition & 427.57 & 385.28 & 0.22 \\
Fans tend to return & 255.03 & 211.74 & 0.20 \\
\hline
\end{tabular}

* Sum of Squares Observations for Mc Non Variant (SSO)

** Sum of Predicted Error Squares for Mc Non Variant (SSE) *** Subscription Validation Index (1-SSE / SSO)

Table 4. Effect of Predictive Variables on Criterion Variable

\begin{tabular}{|lcccc|}
\hline Predictive Variable & $\begin{array}{c}\text { Fans tend to get involved in the competition } \\
\text { t indices }\end{array}$ & $\boldsymbol{\beta}$ indices & \multicolumn{2}{c|}{ Fans tend to return } \\
t indices & $\boldsymbol{\beta}$ indices \\
Attitude & 3.74 & 0.23 & 6.55 & 0.34 \\
Subjective norms & 2.78 & 0.15 & 0.83 & 0.04 \\
Perceived behavior control & 5.93 & 0.35 & 2.37 & 0.16 \\
\hline
\end{tabular}

$-1.96 \leq \mathrm{t}$-value $\leq+1.96$

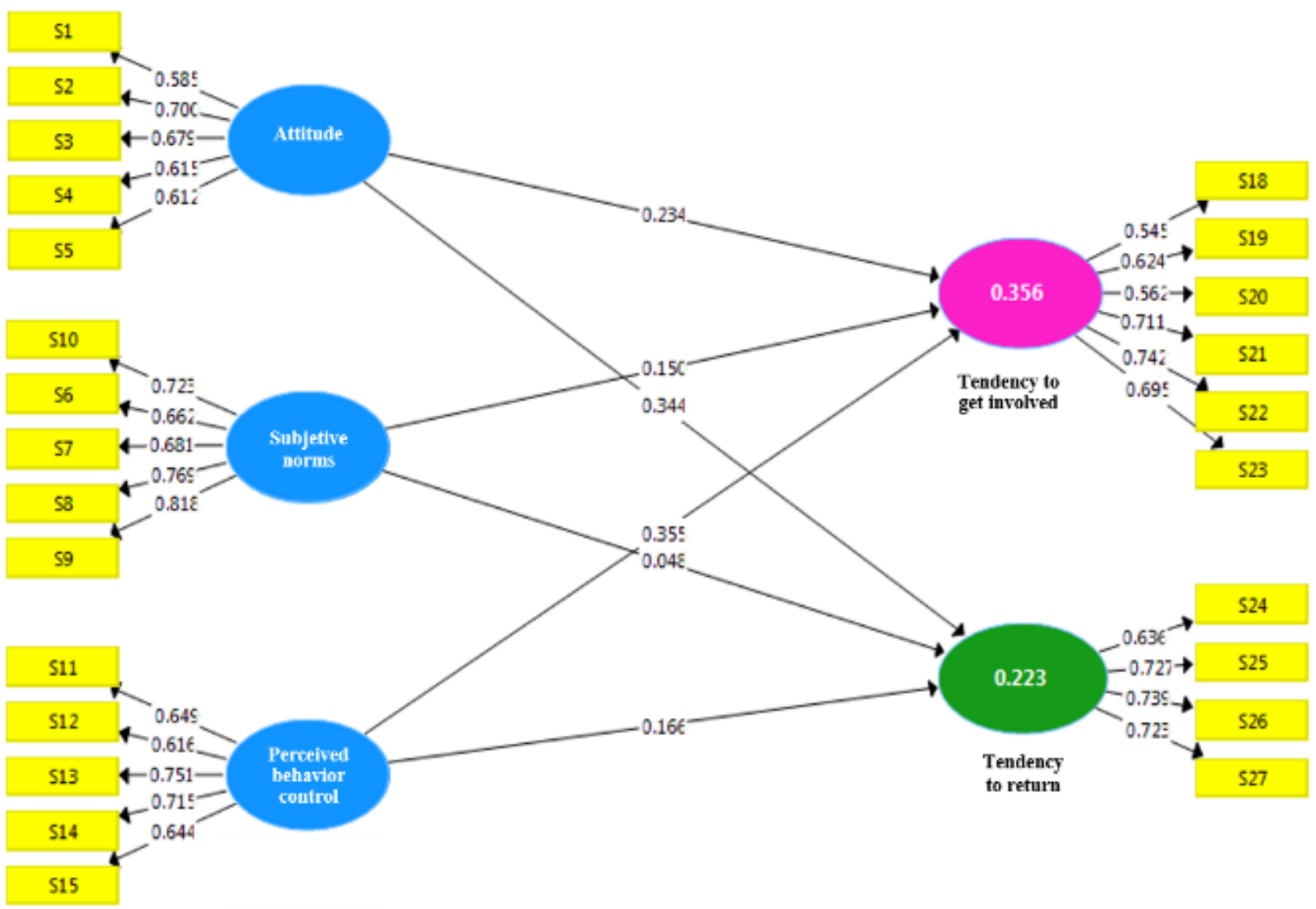

Figure 2. Tested Model in Standard Estimation Mode

According to the results of Table 2, it can be stated that the structures investigated in the present study had a good diagnostic validity. Also, in structural equation modeling using PLS method for measuring quality or fitness of measurement model or, in other words, measuring instruments, the construct cross validated communality was considered. To check this index, the sum of the squares of observations for each latent variable block (SSO) and the sum of the squares of the predicted errors for each latent variable block 
(SSE) were considered. Positive values of this index indicated the appropriate quality of the measuring instruments (48).

According to the results of Tables 2 and 3, it can be stated that the instruments used in the research are of good quality.

Table 4 presents the results of the effect of predictor variables on the research criterion variables. The results showed that the effect of attitude on Involvement of Spectators Horse Racing had a positive and significant effect $(\beta$ $=0.23, \mathrm{t}=3.74)$. The results also showed that subjective norms had a positive and significant effect on the Involvement of Spectators $(\beta=$
$0.15, \mathrm{t}=15.78)$. The effect of perceived behavioral control on the Involvement of Spectators of Horse Racing was positive and significant $(\beta=0.35, \mathrm{t}=5.93)$. Findings showed that attitude had a positive effect on willingness to return of Spectators $(\beta=0.34, \mathrm{t}$ $=6.55)$. The effect of subjective norms on willingness to return of Spectators was not significant $(\beta=0.04, \mathrm{t}=0.83)$. Finally, the positive and significant effect of perceived behavioral control on the willingness to return of Spectators of Horse Racing was confirmed $(\beta=0.16, \mathrm{t}=2.37)$.

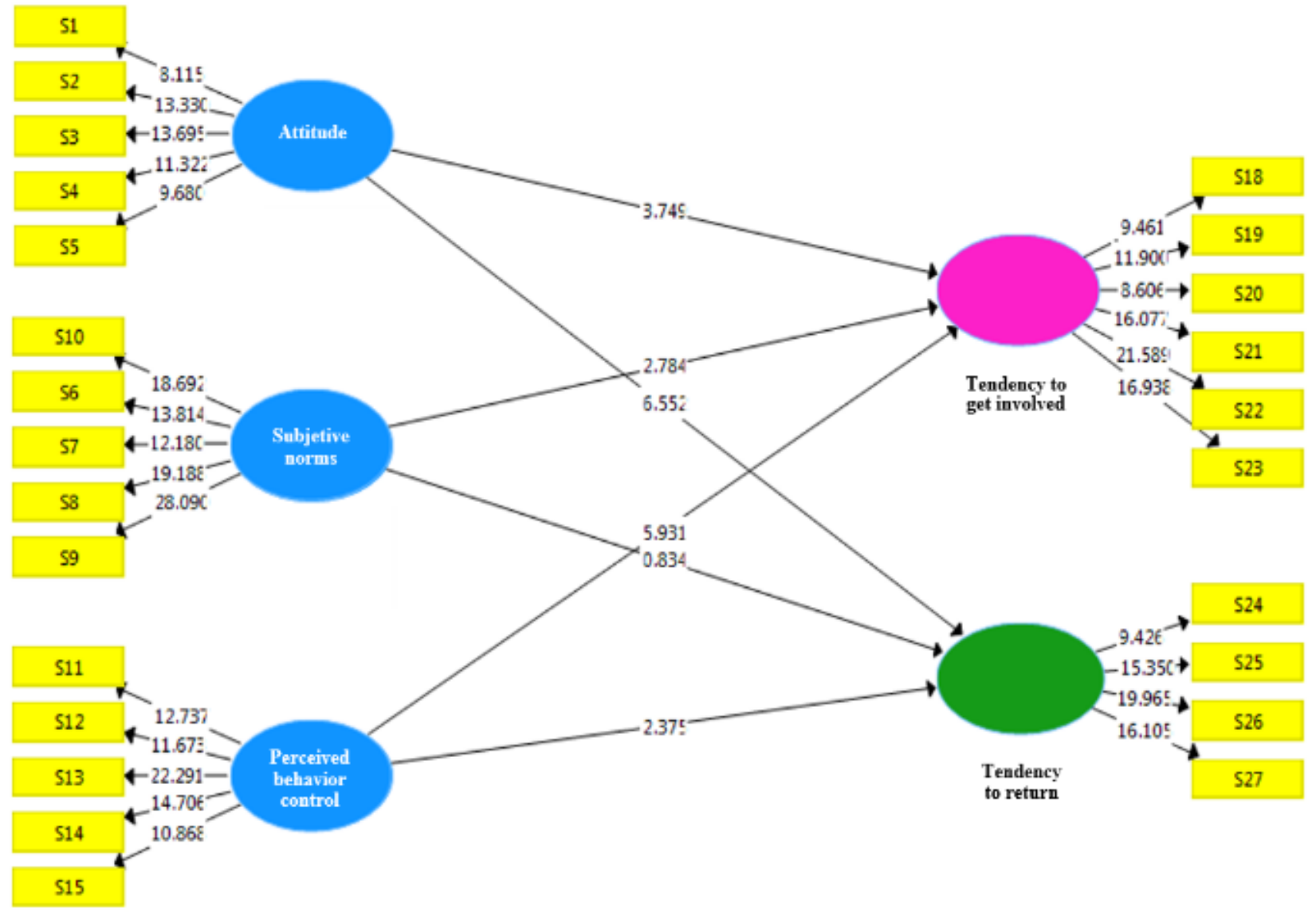

Figure 3. Tested Model in Significant Numbers Mode

\section{DISCUSSION}

The purpose of this study was to model the behavioral tendencies of the Spectators of Horse Racing in the spring period of Gonbad Kavoos based on the planned behavior model. The results showed that the effect of attitude on Involvement of Spectators in the event was positive and significant. This result is consistent with the findings of Bakhshi (2018), Chuan et al (2014) and Cheng et al $(2012)(34,39,40)$. Due to the increasing growth of the sports industry and it's becoming a social trend and participation of community members as a spectator, spectators' presence at sporting events is of particular importance as the most important asset of any event. Therefore, to increase the Involvement of Spectators in a sporting event, the attitude of the Spectators towards the event is very important. According to Chuan et al. (2014), attitude has the ability to predict behavioral goals in sport activities and is positively associated with 
intention of Spectators to participate in sport event (40). Bakhsh results (2018) showed that people who experience positive features of an event such as being fun, exciting, and enjoying an event are more likely to behave more positively on engaging in a sporting event. An attitude generally involves positive or negative feelings about an event, product or service (34).

Findings on attitudes showed the important role of predicting goals in Spectators' behavior for getting Involved in the sport Event and factors such as being entertaining and exciting can influence communication efforts and involvement of Spectators in the event. Therefore, stakeholders of spring competition should strive to create more opportunities such as providing easier attendance at the event, providing the communication links with athletes for Spectators, and helping them to become more involved in the event. Creating these opportunities and effective communication with Spectators can ultimately lead to involvement in the event. Therefore, plans and actions need to be implemented by officials to foster a positive attitude towards Involvement of Spectators in this sporting event. These actions should be based on reinforcing attitudes that increase interest in getting Involved in the Event and should be aimed at enhancing positive attitudes among Spectators.

Another part of the results showed a positive and significant effect of perceived behavioral control on the involvement of Spectators in Horse Racing competition. This result is consistent with the findings of Cheng et al. (2012) and is not consistent with the findings of bakhsh (2018) and Chuan et al. (2014) $(34,40)$.

Perceived behavioral control means the person's perception of how voluntarily is the act controlled by him/her. Perceived behavioral control does not directly predict Spectators' behavior and their involvement in the event. So, if Spectators' behavior is not completely voluntary, even if they are strongly influenced by attitudes and subjective norms, they may not do the act due to conditions interfere. The fact that Spectators of event think they can do simple behavior depends on their ability to control the factors that facilitate or limit the performance of their behavior. Thus, when perceived behavioral control is not a significant predictor of Spectators' intention to engage in selective behavior, it may attract Spectators to specific traits related to another sporting event so they may be attracted to that event. When there is an obstacle for Spectators in a sporting event, perceived behavioral control can only influence Spectators 'behavior through behavioral intent and represent things such as time, traffic, money, and schedule and their direct impact on Spectators' behavioral intentions.

Since sporting events are very important as a sporting product and an important group of its customers are Spectators, which, in addition to giving identity to the event, plays an important role in revenue generation by engaging in the event and buying tickets and given that perceived behavioral control refers to the resources or opportunities that are needed, the officials of the Spring Course can plan appropriately in cases such as the time of the course, attention to traffic issues and transportation of Spectators, attention to timing of city traffic, considering ticket prices and so on to make spectators willing to involve and return to the event.

The results showed that subjective norms had a positive and significant effect on Involvement of Spectators in the event. This result is not in line with the results of Cheng et al (2012) and is in line with the findings of Bakhsh (2018) and Chuan et al (2014) $(34,40)$. Sports Spectators who are willing to spend money on it, are one of the important elements of the success of a sporting event, so, it is important to examine the motivations for attending and engaging in an event in terms of behavioral and influencing factors apart from financial income. The subjective norms of one's perception of whether or not he/she is endorsed or disapproved by people, parents, friends, peers, etc. indicate how much others' opinions influence the person's decision.

Potwarka (2015) stated that after watching an Olympic event, Intention of Spectators to get involved in the Event increased by adding subjective norms, and for participating in an event, Spectators may be heavily influenced by peers, friends, and other important people (33). Officials at horse racing competition must first identify the subjective norms of their Spectators and develop appropriate service strategies to engage Spectators at the event and to satisfy them and increase their loyalty. For example, using strategies such as discounting family tickets, considering family status, etc. for spectators can encourage people to participate with important influential members such as family or peers in the 
event. Proper implementation of such promotional strategies can increase Spectators' involvement in the event and benefit the event promoters. The findings showed that attitude had a positive and significant effect on the willingness to return to horse racing. This result is in agreement with the results of Adousari et al. (2015) and Cunningham and Cowan (2003) and is not in line with $\mathrm{Wu}$ (2015) (42). Attitude toward behavior is a reflection of the result of one's positive or negative evaluation of one's behavior, which is one of the factors affecting the pathways to re-attendance.

Factors affecting the attitude of the Spectators may be internal or external, such as competition events (competitions quality, presence of famous players, entertainment), incentives (cloth color, favorite horses, leisure and entertainment), emotions such as energy use and enjoying with friends. The more positive the Spectators' attitude toward the event, the stronger their intention to return to the event will be. In particular, viewer attitudes are one of the most important predictors of re-attendance in a sporting event. On the other hand, the quality of management and human factors and service personnel of sporting events can increase the likelihood of a return by satisfying the emotional needs of Spectators. Adequate manpower can also provide the conditions for recruiting new Spectators through former Spectators by creating a sense of trust and confidence, in addition to providing incentives for re-attendance of Spectators (49). Therefore, since a positive attitude can play an important role in the desire to return to the spring competition, it is important to increase the Spectators' positive attitude towards sporting events to maximize the likelihood of re-attending the event regardless of prior commitment levels. Accurate identification and reinforcement of factors that enhance a positive attitude to the event are suggested, such as the attractiveness of the event, the presence of strong and beautiful horses, the ability to interact with people, and creating a fun customer atmosphere.

The results showed a positive and significant effect of perceived behavioral control on the willingness of spectators to return to the Gonbad Kavoos Horse Racing. This result is consistent with the results of Aduosari et al. (2015), Wu (2015) and Davons and Hassen Blas (2003). Perceived behavioral control is, in fact, one's beliefs that a behavior is easy or difficult to perform (50). The greater presence of sports spectators and their willingness to return to sporting events increases the sponsor's support in addition to increasing the popularity and attractiveness of the event. At sporting events, when there is no restriction on acceptance of Spectators' specific behavior, Spectators may have complete control over their behavior. On the other hand, for Spectators to control their behaviors, they need internal control factors that are relevant to them (such as skills, abilities, information, emotions) and external control factors (including environmental or occupational factors). If Spectators believe they do not have the resources or facilities to perform a behavior, they probably will not be willing to do so even if they have a positive attitude toward the behavior or people who care about it. When the control over Spectators' behavior is actually understood, the direct impact on the behavior also increases, so perceived behavioral control can tend to increase willingness to return of Spectators.

Therefore, it is necessary to identify the needs of customers in order to have a positive impact on their behavior, considering the interpersonal factors such as skills, abilities and individual differences of individuals and external factors such as event time, leisure time, dependency on others, etc. The results showed that Spectators' subjective norms had no significant effect on their willingness to return to horse racing. This result is consistent with research by $\mathrm{Wu}(2015)$ and not consistent with research by Adusari et al. (2015), Davons and Hassen Blas (2003) and Cunningham and Cowan (2003) (42, 50). Subjective norms refer to the interaction or non-interaction of the individual with respect to others, and the individual adjusts his or her behavior to the behavior and needs of the group considered as reference. The reason for this discrepancy may be that subjective norms are not related to the intention of the Spectators to behave and do not directly affect their behavior. So the decision to re-attending and the desire to return to a sporting event among the highly committed fans is largely based on their personal preference rather than the opinion of other important individuals. The reason for this priority can be traced back to the roots, history and culture of the Gonbad Kavoos people, and especially Turkmen. Horses and horse racing are found in the roots of the people of this area. Since the Horse racing is thrilling and has one of the largest sports community, and although Spectators may not be influenced by other people 
who encourage him/her to participate in the sporting event, it is almost impossible for them to participate alone and being away from the influence of other important people.

Since most studies have confirmed the influence of subjective norms on the willingness and intention of Spectators to return, and can play an important role in the re-attendance Spectators to sporting events, so understanding how Spectators are influenced by others is relative. The reactions of relatives, acquaintances and those around them that respond to and feel about the event are important. As their attitudes toward sporting events differ, practitioners of the horse racing competition should use different ways to interact with influential individuals including identifying Spectators key priorities, needs and desires, as well as strengthening the interaction between Spectators and the people who are important to them.

\section{CONCLUSION}

The results of this study showed that the effect of attitude, subjective norms and perceived behavior control were positive and significant on Horse Racing Involvement of Spectators. Moreover, the effect of attitude and perceived behavior control was positive and significant on Spectators re-attendance and the effect of subjective norms on was not significant on Spectators re-attendance.

In this study, only the effect of planned behavior model on Behavioral Tendencies of the Spectators was investigated which can be considered as one of the limitations of this study. It is recommended that future research consider other factors influencing Behavioral Tendencies of the Spectators such as subjective imagery, perceived values of the event, and event identity.

\section{APPLICABLE REMARKS}

- Implementing advertising strategies that increase Spectators' involvement in the event.

- Allocating family-friendly venues that increase the likelihood of Spectators re-attendance to the event.

- Introducing fun programs for Spectators before the race begins.

- Increasing Spectators' knowledge of the horse industry (all types of competitions, breeds, job opportunities, etc.) through booklets or workshops for Spectators and the general public.

- Providing comprehensive information on all types of racing in the field during Horse Racing and creating a comprehensive website on Horse Racing in Gonbad Kavoos (information on spring and fall competitions, tournament history, tournament results, introduction of Horse Clubs, Introducing Famous Athletes in the Field)

- Considering a post-race time for Spectators to keep in touch with horse owners as well as the riders.

- Organizing social events before and during the tournament, such as honoring the oldest and youngest spectator of the week.

- Performing cultural and traditional events during these competitions such as Turkmen and Persian music to create a positive image of the event in the minds of the Spectators.

\section{REFERENCES}

1. Zhang JJ, Kim E, Mastromartino B, Qian TY, Nauright J. The sport industry in growing economies: critical issues and challenges. Int J Sports Market Sponsorsh. 2018;19(2):110-126. doi: 10.1108/ijsms03-2018-0023

2. Stander FW, van Zyl LE. See you at the match: Motivation for sport consumption and intrinsic psychological reward of premier football league spectators in South Africa. Sa J Ind Psychol. 2016;42(1). doi: 10.4102/sajip.v42i3.1312

3. Wang Y, Zhang JJ, Pifer ND, Kim M. Factors affecting the regional strategies for developing and advancing the Chinese sport industry. Int J Sports Market Sponsorsh. 2018;19(2):178-193. doi: 10.1108/ijsms-08-2017-0082

4. Clingan E. The relationship of online sports site participation with fan and commentator self-identities. Elon J Undergrad Res Commun. 2011;2:43-57.

5. Biscaia R. Revisiting the Role of Football Spectators' Behavioral Intentions and its Antecedents. Open Sports Sci J. 2016;9(1):3-12. doi: 10.2174/1875399x01609010003

6. Yoshida M, James JD. Customer Satisfaction With Game and Service Experiences: Antecedents and Consequences. J Sport Manage. 2010;24(3):338-361. doi: 10.1123/jsm.24.3.338 
7. Biscaia R, Correia A, Yoshida M, Rosado A, Marôco J. The role of service quality and ticket pricing on satisfaction and behavioural intention within professional football. Int J Sports Market Sponsorsh. 2013;14(4):42-66. doi: 10.1108/ijsms-14-04-2013-b004

8. Theodorakis ND, Alexandris K, Tsigilis N, Karvounis S. Predicting spectators' behavioural intentions in professional football: The role of satisfaction and service quality. Sport Manage Rev 2013;16(1):8596. doi: 10.1016/j.smr.2012.05.004

9. Abdulmaleki H. Designing a consumer behavior model in the country's sports industry. Mashhad: Ferdowsi University of Mashhad; 2016.

10.Jin NP, Lee S, Lee H. The Effect of Experience Quality on Perceived Value, Satisfaction, Image and Behavioral Intention of Water Park Patrons: New versus Repeat Visitors. Int J Tour Res. 2015;17(1):8295. doi: 10.1002/jtr.1968

11. Kim JW, James JD, Kim YK. A model of the relationship among sport consumer motives, spectator commitment, and behavioral intentions. Sport Manage Rev. 2013;16(2):173-185. doi: 10.1016/j.smr.2012.08.004

12. Turhan G, Özbek A. Factors affecting consumers' behavioural intention towards apparel stores: A test of the mediating role of brand satisfaction. Fibres Textiles East Eur. 2013.

13. Beaton AA, Funk DC, Ridinger L, Jordan J. Sport involvement: A conceptual and empirical analysis. Sport Manage Rev. 2011;14(2):126-140. doi: 10.1016/j.smr.2010.07.002

14. Chao-Sen W, Nunkoo R. Application of TQM to road races: Study on the sports involvement and willingness to re-participate. Cogent Busin Manage 2018;5(1). doi: 10.1080/23311975.2018.1509811

15. Schiffman L, Kanuk L. Consumer Behaviour: Prentice-Hall; 2010.

16. Hallmann K, Zehrer A. Event and community involvement of sport event volunteers. Int J Event Fest Manage. 2017;8(3):308-323. doi: 10.1108/ijefm-08-2016-0058

17.Lin C, Feng Y. A study of leisure involvement, flow experience and well-being in sport of tennis participants. J Chiao Da Phys Educ. 2015;10:1-12.

18. Kim YK, Trail G. Constraints and Motivators: A New Model to Explain Sport Consumer Behavior. $J$ Sport Manage. 2010;24(2):190-210. doi: 10.1123/jsm.24.2.190

19.Ha J-H, Han J-W. Influence of Affective Reaction, Cognition, Spectator Satisfaction, Psychological Commitment on Intention to Attend Future Games to a Collegiate Sports Team. J Sport Leis Stud. 2010;39:223-237.

20. Dhurup M, Mofoka MA, Surujlal J. The relationship between stadium sportscapes dimensions, desire to stay and future attendance. Afr $J$ Phys Health Educ Recreat Dance. 2010;16(3). doi: 10.4314/ajpherd.v16i3.60925

21.Lee J-H, Kim H-D, Ko YJ, Sagas M. The influence of service quality on satisfaction and intention: A gender segmentation strategy. Sport Manage Rev. 2011;14(1):54-63. doi: 10.1016/j.smr.2010.02.002

22. Byon KK, Zhang JJ, Baker TA. Impact of core and peripheral service quality on consumption behavior of professional team sport spectators as mediated by perceived value. Eur Sport Manage $Q$. 2013;13(2):232-263. doi: 10.1080/16184742.2013.767278

23. Calabuig Moreno F, Prado-Gascó V, Crespo Hervás J, Núñez-Pomar J, Añó Sanz V. Spectator emotions: Effects on quality, satisfaction, value, and future intentions. J Busin Res 2015;68(7):1445-1449. doi: 10.1016/j.jbusres.2015.01.031

24.K. Byon K, Lee S, A. Baker T. A cross-cultural study of purchase intention of sponsored products based on American and Korean spectators of the 2010 FIFA World Cup South Africa. Sport Busin Manage Int J. 2014;4(2):158-177. doi: 10.1108/sbm-04-2013-0005

25.Eddosary M, Ko YJ, Sagas M, Kim HY. Consumers' Intention to Attend Soccer Events: Application and Extension of the Theory of Planned Behavior. Psychol Rep. 2015;117(1):89-102. doi: 10.2466/01.05.PR0.117c13z7 pmid: 26241095

26. Carmen Neipp M, José Quiles M, Rodríguez-Marín J. Theory of Planned Behavior and physical exercise: Differences between people who do regular physical exercise and those who do not. $J$ Klagenfurt. 2013;20(10):324-335.

27. Choi Y, Martin J, Park M, Yoh T. Motivational Factors Influencing Sport Spectator Involvement At NCAA Division II Basketball Games. J Study Sports Athletes Educ. 2013;3(3):265-284. doi: 10.1179/ssa.2009.3.3.265 
28.Luszczynska A, Schwarzer R, Lippke S, Mazurkiewicz M. Self-efficacy as a moderator of the planningbehaviour relationship in interventions designed to promote physical activity. Psychol Health. 2011;26(2):151-166. doi: 10.1080/08870446.2011.531571 pmid: 21318927

29. Vo PT, Bogg T. Testing Theory of Planned Behavior and Neo-Socioanalytic Theory models of trait activity, industriousness, exercise social cognitions, exercise intentions, and physical activity in a representative U.S. sample. Front Psychol. 2015;6:1114. doi: 10.3389/fpsyg.2015.01114 pmid: 26300811

30.Plotnikoff RC, Lippke S, Courneya K, Birkett N, Sigal R. Physical activity and diabetes: an application of the theory of planned behaviour to explain physical activity for Type 1 and Type 2 diabetes in an adult population sample. Psychol Health. 2010;25(1):7-23. doi: 10.1080/08870440802160984 pmid: 20391204

31.Leavell JP. Contolling and Informational Planned Behavior: Self-Determination Theory and the Theory of Planned Behavior. Atlantic Market J. 2015;5(3):81-91.

32.Lu WC, Lin SH, Cheng CF. Sports spectator behavior: a test of the theory of planned behavior. Percept Mot Skills. 2011;113(3):1017-1026. doi: 10.2466/05.17.PMS.113.6.1017-1026 pmid: 22403943

33.Potwarka LR. Exploring Physical Activity Intention as a Response to the Vancouver Olympics: an Application and Extension of the Theory of Planned Behavior. Event Manage 2015;19(1):73-92. doi: $10.3727 / 152599515 \times 14229071393025$

34.Bakhsh J. Understanding a Demonstration Effect Among Youth Sport Spectators: An Application and Augmentation of the Theory of Planned Behavior: University of Waterloo; 2018.

35.Potwarka L, McCarville R. Exploring the trickle-down effect of the Olympics on activity levels within host nations: Suggestions for research and practice. Int Sport Res Synth. 2010:179-190.

36. Naylor M. An Alternate Conceptualization of the Theory of Planned Behavior in the Context of Sport Participation. Florida Florida State University; 2011.

37.Parsamehr M. Investigating the motivations of individuals for their intention to participate in sports activities (Experimental Test of Planned Behavior Theory). Two Res Projects Sport Manage Motor Behav. 2014;8:21-35.

38. Motalebi A, Amirzadeh Iranagh J, Abdollahi A, Konglim W. Applying of theory of planned behavior to promote physical activity and exercise behavior among older adults. J Phys Educ Sport. 2014;14(4):562568.

39. Cheng C-F, Chen LH, Chen M-Y, Lu W-C. Fan participation behaviour in baseball: an application of the theory of planned behaviour. Int J Sports Market Sponsorsh. 2012;14(1):17-28. doi: 10.1108/ijsms14-01-2012-b003

40. Chuan CC, Yusof A, Soon CC, Abdullah MC. Application of theory of planned behavior to predict recreational sports activities participation of students in Malaysia. J Phys Educ Sport. 2014;14(2):172.

41. Sumida K, Fujimoto J, Sakata M. Differentiating attitudes: team loyalty and attitude towards spectating behaviour. Sport Busin Manage Int J. 2014;4(2):109-124. doi: 10.1108/sbm-02-2011-0024

42. Wu C-L. Using The Theory Of Planned Behavior To Explain And Predict Behavior Intentions in Taiwan. J Int Educ Res 2015;11(3):153-162. doi: 10.19030/jier.v11i3.9366

43. Kim MS, James J. The theory of planned behaviour and intention of purchase sport team licensed merchandise. Sport Busin Manage Int J. 2016;6(2):228-243. doi: 10.1108/sbm-02-2014-0005

44. Roult R, Lavigne M-A, Auger D. The horse racing industry in Canada: current status and prospects. Manag Sport Leis. 2017;22(1):19-32. doi: 10.1080/23750472.2017.1338534

45. Riess S. The Cyclical History of Horse Racing: The USA's Oldest and (Sometimes) Most Popular Spectator Sport. Int J Hist Sport. 2014;31(1-2):29-54. doi: 10.1080/09523367.2013.862520

46.Davari A, Rezazadeh A. Structural Equation Modeling With PLS. Tehran: Organization Jahad Daneshgahi Publication; 2014.

47.Fornell C, Larcker DF. Evaluating Structural Equation Models with Unobservable Variables and Measurement Error. J Market Res. 1981;18(1):39. doi: 10.2307/3151312

48. Seyed Abaszadeh M, Amani Sarigloo G, Khezri Azar H, Pashuy G. An Introduction to Structural Equation Modeling by PLS Method and Its Application in Behavioral Sciences. Urmia: Urmia University Press; 2012. 
49. Rozita AL, Zana AAN, Khairulzaman H, Norlizah AH. Impact of Sport Complex Services towards Costumer Behaviour in Terengganu. Proc Soc Behav Sci. 2014;153:410-418. doi: 10.1016/j.sbspro.2014.10.074

50.Ajzen I. Perceived Behavioral Control, Self-Efficacy, Locus of Control, and the Theory of Planned Behavior1. J Appl Soc Psychol 2002;32(4):665-683. doi: 10.1111/j.1559-1816.2002.tb00236.x 